American Journal of Applied Sciences 4 (9): 725-735, 2007

ISSN 1546-9239

(C) 2007 Science Publications

\title{
Finite Element and Experimental Serviceability Analysis of HSC Beams Strengthened with FRP Sheets
}

\author{
Seyed Hamid Hashemi, Reza Rahgozar and Ali Akbar Maghsoudi \\ Professor, Department of Civil Engineering, University of Kerman, PO Box 76169- \\ 14111, Kerman, Iran
}

\begin{abstract}
The use of externally bonded composite sheets or laminates is by now a diffuse technique to strengthen existing RC structures. However, some aspects of flexural condition still need experimental and numerical analysis; furthermore, especially for serviceability checks, there is a lack of code provisions. Six reinforced high strength concrete (HSC) beams strengthened with FRP sheets were fabricated and tested, the finite element (FE) models adopted by ANSYS was performed to examine the structural behavior of tested beams was performed. A comparison between the finite element analysis results and the experimental data available on the specimens was made and by using trial and error method, the finite element model was calibrated. Six under-reinforced concrete beams were fabricated and tested to failure. With the exception of the control beam, one or four layers of CFRP were applied to the specimens. The structural response throughout the loading regime was primarily captured in terms of the load deflection behavior. The load deflection plots obtained from numerical study show good agreement with the experimental results. The serviceability characteristics of the test beams were evaluated in terms of the crack width, deflection and stress in steel and concrete. The crack patterns in the beams are also presented.
\end{abstract}

Keywords: Finite Element Model, FRP, HSC, Serviceability

\section{INTRODUCTION}

The high strength-to-weight ratio, resistance to electro-chemical corrosion, larger creep strain, good fatigue strength, potential for decreased installation costs and repairs due to lower weight in comparison with steel, and nonmagnetic and non-metallic properties of fiber reinforced polymer (FRP) composites offer a viable alternative to bonding of steel plates. The emergence of high strength epoxies has also enhanced the feasibility of using CFRP sheets and carbon fiber fabric for repair and rehabilitation.

The failure modes of concrete beams retrofitted with FRP materials and the techniques used in analyzing the failure modes were reviewed by Toutanji et al. ${ }^{[1]}$ and Xiong et al. ${ }^{[2]}$. The behavior of concrete beams strengthened with externally bonded steel plates ${ }^{[3]}$, FRP plates ${ }^{[4-6]}$, carbon fiber fabric ${ }^{[7]}$ and GFRP sheets ${ }^{[8]}$ was studied both experimentally and analytically. Malek et al. ${ }^{[9]}$ presented analytical and Kachlakev et al. ${ }^{[10]}$ presented numerical finite element procedures to calculate the flexural strength of $\mathrm{RC}$ beams bonded with FRP plates. To date, extensive research work has been conducted on the flexural strength of concrete beams bonded with various types of FRP composites ${ }^{[11,12]}$.

The realistic, practical modelling of steel and reinforced concrete beams is one of the most important problems in structural analysis. Finite element procedures are at present widely used in engineering modelling and analysis and are employed extensively in the analysis of solids and structures. The essence of a finite element solution of an engineering problem is that a set of governing algebraic equations is established which are then solved with the help of a digital computer. The first practical finite element procedures were employed in the linear analysis of solids and structures with the implicit assumption being that the structures or bodies under consideration are elastic and obey Hooke's law throughout the loading regime. It is however well established that the stress strain relationship for a number of structural materials, for example concrete, is nonlinear. Thus, even though in a typical reinforced concrete member the displacements and strains are infinitesimally small, thus ruling out kinematical non-linear effects, the material nonlinearity induced due to non-linear stress strain relations of the constitutive materials, cracking of the concrete
Corresponding Author:
Seyed Hamid Hashemi, Department of Civil Engineering, University of Kerman, PO Box: 76169-14111, Kerman, Iran, Tel: +98-9126177516, Fax: +98-341-3220054 
and plasticity of the reinforcement and of the compression concrete have to be incorporated so as to realistically analysis the structural response throughout the loading regime. Performing a nonlinear analysis is imperative for evaluation of structural response in terms of complete load-deflection characteristics, ductility and mode of failure etc. particularly for earthquake engineering applications. A wide range of commercially available software like DIANA, ADINA, ATENA and ANSYS etc. incorporate finite element based nonlinear analysis capabilities incorporating both material and kinematics nonlinearities. In this paper an attempt has been made with the ANSYS software to bring into focus the versatility and powerful analytical capabilities of nonlinear FE techniques by objectively modelling the complete response of test beams.

The objective of this investigation is to study the effectiveness of FRP sheets on serviceability of reinforced high strength concrete (HSC) beams. This objective is achieved by conducting the following tasks: (1) flexural testing of reinforced HSC beams strengthened with different amounts of cross-ply of FRP sheets with different amount of tensile reinforcement; (2) calculating the effect of different layouts of FRP sheets on the flexural strength; (3) Evaluating the crack width and deflection (serviceability considerations) and (4) threedimensional nonlinear finite element models are developed to examine the test beams behavior.

\section{HSC LABORATORY BEAM SPECIMENS}

Beam detail, measurement and test scheme: Fourpoint bending flexural tests were conducted up to failure on two reinforced HSC control beams and four reinforced HSC beams strengthened with externally bonded FRP sheets on the tension face. The length, width, and depth $(\mathrm{L} \times \mathrm{b} \times \mathrm{h})$ of all beams were kept as $3000 \times 150 \times 250 \mathrm{~mm}$. Each concrete beam was reinforced with two 16-mm diameter for A series and two 22-mm diameter for B series steel bars for tension and two $10-\mathrm{mm}$-diameter steel bars for compression along with $10-\mathrm{mm}$-diameter bars at a spacing of $90 \mathrm{~mm}$ center-to-center for shear reinforcement. The spacing of stirrups and maximum and minimum reinforcement ratios are in accordance with the provision of the American Concrete Institute (ACI 318-05) [13].

Electrical resistance disposable strain gauges were pasted on the CFRP sheets and on internal reinforcing bars at different locations. The demec and electrical gauges were also attached along the height of beams to measure the concrete strains; these values can be used to find out the strain distribution and the moving neutral axis depth of the beams tested. All beams were loaded in four-point bending to failure with a clear span of 2.7 $\mathrm{m}$, and loading points were located at $450 \mathrm{~mm}$ on either side of the mid-span location (Fig. 1). The load was applied step-by-step in a load control manner of test beams. During the test, the strains on steel and concrete, and vertical deflections were measured using LVDTs (Fig. 2). For all beams, the shear-span-to-depth ratios are 4.18 and the length of the bonded plate is $2600 \mathrm{~mm}$, which covers almost the full-span length between the supports of the beams. The reason for the full-spanlength strengthening with FRP plates is to maximize the strengthening effects by delaying the FRP separation.

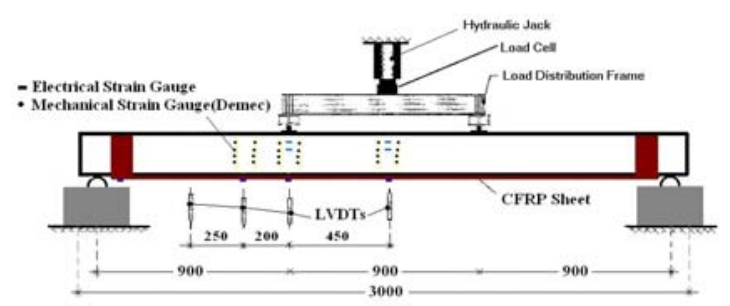

Fig. 1: Details of Loading System and Measurement Schemes (unit: millimetre)

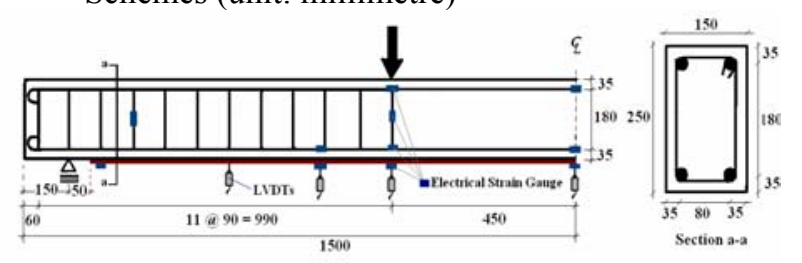

Fig. 2: Beam Details and Measurement Schemes for Half of the Test Specimen (unit: millimetre)

Material properties: The concrete strength of each beam was measured by three $100 \mathrm{~mm} \times 100 \mathrm{~mm} \times 100 \mathrm{~mm}$ concrete cube specimens made at the time of casting and were kept with the beams during curing. The average 28-day concrete cube strength $\left(f_{c u}\right)$ was 96.2 MPa. The relationship of cylinder strength $\left(f_{c}^{\prime}\right)$ and cube strength assumed as $\left(f_{c}^{\prime}=0.8 f_{c u}\right)$ and thus the average compressive strength $\left(f_{c}^{\prime}\right)$ was $77 \mathrm{MPa}$.

The measured yield and maximum tensile strength of the 10 and $16 \mathrm{~mm}$ rebar was $420.6,634.1$ and 412.5, 626.4 MPa respectively. The density and thickness of the CFRP material was $1.78 \pm 0.1 \mathrm{gr} / \mathrm{cm}^{3}$ and 0.045 $\mathrm{mm}$ respectively and $2600 \mathrm{~mm}$ long. The Young's modulus $\left(E_{f u}\right)$, ultimate tensile stress $\left(f_{f u}\right)$ and elongation $\left(\varepsilon_{f u}\right)$ of the FRP sheets were $230 \mathrm{GPa}, 3850 \mathrm{MPa}$ and $1.7 \pm 0.1 \%$ respectively. FRP sheets externally bonded to the tension face of the concrete beams using a twocomponent structural epoxy named EP-TX at 1:1 ratio 
for the first layer and a two-part epoxy named EP-IN at 1:1 ratio for the next layer(s) of FRP. Strengthened concrete beams were cured for at least seven days at room temperature before testing.

Major test variables: The main test variables considered in the present study include the FRP sheet layers and tensile bars. The FRP sheet layers varies from 0 to 4 and the bar reinforcement ratio varies from $1.2 \%$ to $2.4 \%$. The test program is summarized in Table 1. Of the six beams tested, two were set aside as control beams and were not strengthened ( $\mathrm{AH} 0, \mathrm{BH})$ ), two beam were strengthened with one layer of CFRP (AH1, BH1) and two beam strengthened with four layer of CFRP (AH4, BH4) where the width of CFRP was 150 $\mathrm{mm}$.

Table 1: Test Parameters and Specimen Identifications

\begin{tabular}{cccc}
\hline $\begin{array}{c}\text { Test } \\
\text { beam }\end{array}$ & $A_{S}$ & $\begin{array}{c}\mathrm{A}_{\mathrm{FRP}} \\
\left(\mathrm{mm}^{2}\right)\end{array}$ & $\begin{array}{c}\text { FRP detail } \\
(\text { layers } \times \text { thickness } \times \text { width })\end{array}$ \\
\hline AH0 & $2 \Phi 16$ & 0 & 0 \\
$\mathrm{AH} 1$ & $2 \Phi 16$ & 6.75 & $(1 \times 0.045 \times 150)_{\text {CFRP }}$ \\
AH4 & $2 \Phi 16$ & 27 & $(4 \times 0.045 \times 150)_{\text {CFRP }}$ \\
BH0 & $2 \Phi 22$ & 0 & 0 \\
BH1 & $2 \Phi 22$ & 6.75 & $(1 \times 0.045 \times 150)_{\text {CFRP }}$ \\
BH4 & $2 \Phi 22$ & 27 & $(4 \times 0.045 \times 150)_{\text {CFRP }}$ \\
\hline
\end{tabular}

\section{MODELLING METHODOLOGY AND FINITE ELEMENT ANALYSIS APPROACH}

FE analysis is performed using ANSYS ${ }^{[14]}$, a general purpose finite element program. The status transition of concrete from an uncracked to cracked state and the nonlinear material properties of concrete in compression and steel as it yields cause the nonlinear behavior of the structures under loading. NewtonRaphson equilibrium iteration is used to solve nonlinear problem in ANSYS. In a linear analysis the size of the load increment does not affect the results at all. However, for a nonlinear analysis, in which FE structures start cracking and behave nonlinearly under a sufficiently large load, the load applied to the structures must be increased gradually to avoid non-convergence. Tolerances in both force and displacement criteria may have to be gradually increased along the loading history to avoid a diverged solution.

\section{MATERIAL MODELING}

Concrete: The SOLID65 ${ }^{[14]}$, three-dimensional (3D) reinforced concrete solid element, is used to represent concrete in the models. The element, using a $2 \times 2 \times 2$ set of Gaussian integration points, is defined by eight nodes having three translational degrees of freedom at each node. This element is capable of cracking in tension and crushing in compression, although the crushing capability of the element is not used in this study. The most important implementation of the SOLID65 element is the proper definition of nonlinear material properties. The responses of concrete under loading are characterized by distinct nonlinear behavior. Complete stress-strain curves for concrete are needed to accurately predict a whole range of beams behavior from service loading up to failure and postfailure responses. Additionally, the descending branch is needed since a portion of the concrete compression zone is usually in this range of strains at the ultimate limit state.

The stress-strain curve here is nearly linearly elastic up to the maximum tensile strength. After this point, the concrete cracks and the strength decrease gradually to zero. The uniaxial stress-strain behavior of concrete has been proposed by many empirical formulas. The simplest of the linearly elastic-perfectly plastic model which used by ${ }^{[15]}$ and in this study, is shown in Fig. 3.

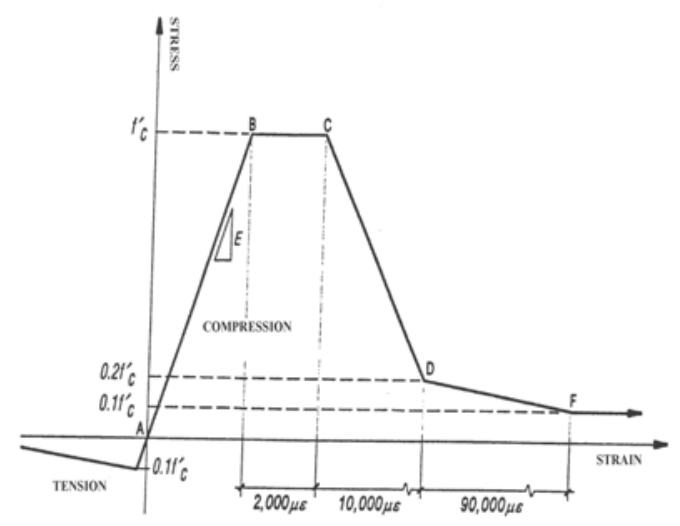

Fig. 3: Concrete stress-strain curve ${ }^{[15]}$

In this study due to symmetry, only one loading plate and one support plate are needed. The support is a $5 \times 15 \times 2 \mathrm{~cm}$ steel plate, while the plate at the load point is $10 \times 15 \times 2 \mathrm{~cm}$. The combined volumes of the plate, support, and beam with the FE mesh for half length of the beam model is shown in Fig. 4. 


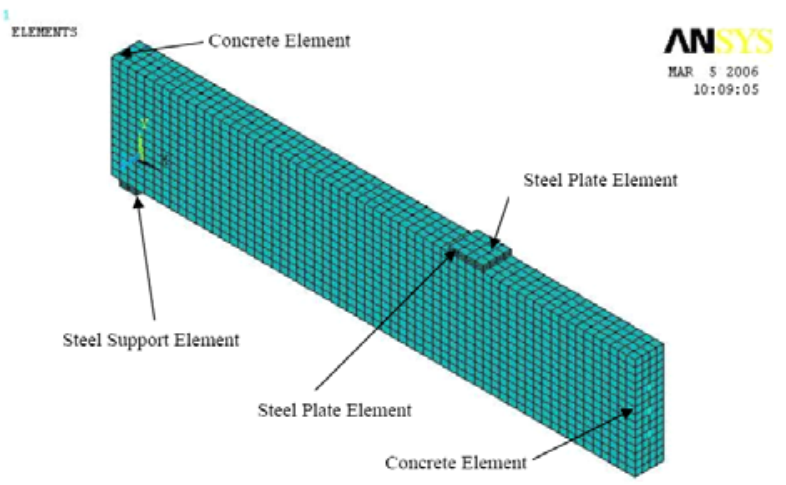

Fig. 4: FE Mesh of Concrete, Steel Load Plate and Steel Support Plate

Reinforcing steel: The LINK8, 3-D spar element, is used to represent the reinforcing steel bar. It is a uniaxial tension-compression that can also include nonlinear material properties. Two nodes having three degrees of freedom at each node, as in the SOLID65 element, define the element. The elastic-perfectly plastic representation is assumed for the reinforcing steel bars in this study.

Fiber-reinforced polymer: The SOLID46, 3D layered structural solid element, is used to represent the FRP materials. The element has eight nodes with three translational DOFs at each node. Assuming perfect interlaminate bond, no slippage is allowed between the element layers. The FRP laminates are considered brittle materials, and the stress-strain relationship is roughly linear up to failure. Consequently, in this study it is assumed that the stress-strain relationships for the FRP laminates are linearly elastic.

Analysis assumptions: The following are the general analysis assumptions made for the test beam models in this study to provide reasonable simulations for the complex behavior:

1. The bond between each element/material type are assumed perfect; that is, there is no slippage between concrete and reinforcing steel bars, between concrete and FRP laminates, and between different FRP layers. Unless the failure mode of a structure involves a bond failure, the perfect bond assumption used in the structural modeling will not cause a significant error in the predicted load-deflection response specially while considering serviceability study.

2. A constant Poisson's ratio of 0.2 is assumed for concrete throughout the loading history.

3 . For the shear transfer coefficients, $\beta$, for closed and open cracks in the SOLID65 element, values can range from 0.0 to 1.0. A value of 0.0 refers to a smooth crack, while 1.0 refers to a rough crack. These factors are used to determine how much shear force can be transferred across open or closed cracks. For closed cracks, $\beta$ is always assumed to equal 1.0. However, for an open crack, $\beta$ varies from 0.05 to 0.5 and in this study; a $\beta$ value of 0.2 for open cracks is used. This value is selected based on results in ${ }^{[16]}$.

4. The concrete is assumed to be isotropic prior to cracking and orthotropic after cracking. The steel is assumed to be isotropic. The FRP material is assumed to be specially orthotropic, transversely isotropic. That is, the material properties in the two directions that are both perpendicular to the fiber direction are identical.

5. Time-dependent nonlinearities such as creep, shrinkage, and temperature change are not included in this study. However for HSC; these values are generally lower than normal concrete ${ }^{[17]}$.

\section{COMPARISONS BETWEEN EXPERIMENTAL DATA AND NUMERICAL RESULTS}

Load- displacement curves: In this section, the numerical results for all specimens are presented and compared with experimental values that for each beam the load-displacement curve plotted until the load values are equal to tensile bar reinforcement yield load. Figures 5 and 6 contain a comparison between the loaddisplacement curves predicted by ANSYS and the test results for all specimens at mid-span section (sec1-1). As is seen, the agreement is reasonable. The results of ANSYS match the plain specimen better than the strengthened specimens. This may be a result of bond slip between FRP and concrete that is ignored in the current analysis.

In general, the strengthened beams were stiffer than the control specimens (see $\mathrm{BH} 0$ and $\mathrm{BH} 4$ ). As a result compared to a beam reinforced with steel only (see BH0 in Fig. 6), beams reinforced with steel and strengthening with CFRP (see AH1 or AH4 in Fig. 5) have adequate deformation capacity in serviceability limit state.

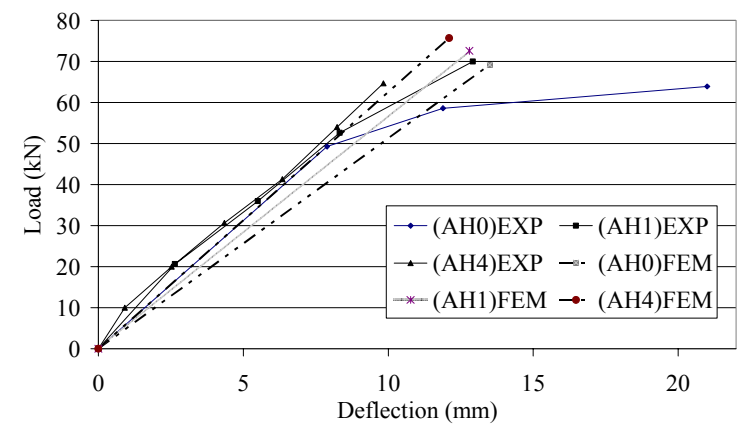

Fig. 5: Comparison between load-displacement curves predicted by ANSYS and the test result for the A group specimens at mid-span section

The strain response of FRPs is different from that 
of conventional steel, which yields after elastically deforming to relatively small values of strain $(0.2 \%$ and $0.14 \%$ for Grade 60 and 40 (i.e., 410 and $280 \mathrm{MPa}$ ); FRP materials exhibit elastic deformation to relatively large strain values before rupture. As a result, when FRPs are used for flexural strengthening of concrete beams reinforced with conventional steel, the steel rebar may yield before the FRP contributes any additional capacity to the beam. Therefore, it is difficult to obtain a significant increase in yield load or stiffness of the beam. When an increase in beam yield load or stiffness is required, larger cross sections of FRPs must be used (before the steel yields), which generally increases the cost of strengthening. Although using some special, low-strain fibers, such as ultra-highmodulus carbon fibers may appear to be a solution; they can result in brittle failures due to fiber failure. Taking advantage of the high strength of FRPs during flexural strengthening of RC beams is limited by the bond capacity between them and the concrete surface.

As the amount of steel reinforcement increase, the less is decreased in deflection provided by the FRP external reinforcement. The same amount of CFRP reinforcement decrease more than $53 \%$ of the yield deflection for a lightly reinforced beam (A series test beam, $\rho=1.2 \%$ ), but only decreased $3.6 \%$ of the yield deflection for a moderately reinforced beam (B series test beam, $\rho=2.4 \%$ ).

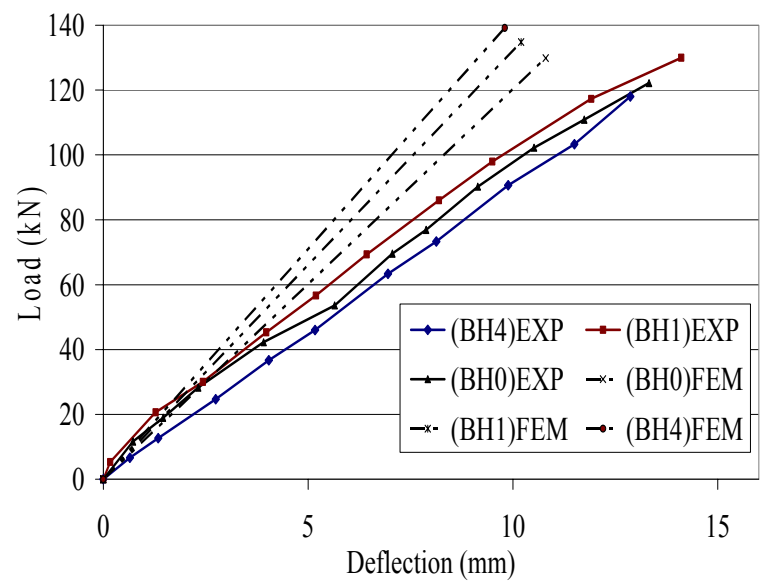

Fig. 6: Comparison between load-displacement curves predicted by ANSYS and the test result for the B group specimens at mid-span section

The predicted results at yield stage are compared with the experimental load and deflection, shown in Table 2.

Table 2: Experimental and numerical yield stage loaddeflection results for mid-span section

\begin{tabular}{|c|c|c|c|c|c|c|}
\hline \multirow[b]{2}{*}{$\begin{array}{l}\text { Test } \\
\text { Beam }\end{array}$} & \multicolumn{3}{|c|}{$\begin{array}{l}\text { Load at Yield } \\
\text { Stage }(\mathrm{kN})\end{array}$} & \multicolumn{3}{|c|}{$\begin{array}{l}\text { Deflection at Yield Stage } \\
(\mathrm{mm})\end{array}$} \\
\hline & $\begin{array}{l}E \\
X \\
P\end{array}$ & $\begin{array}{l}\mathrm{FE} \\
\mathrm{M}\end{array}$ & $\begin{array}{l}\mathrm{E} \\
\mathrm{X} \\
\mathrm{P} \\
/ \\
\mathrm{F} \\
\mathrm{E} \\
\mathrm{M}\end{array}$ & EXP & $\begin{array}{l}\mathrm{F} \\
\mathrm{E} \\
\mathrm{M}\end{array}$ & $\begin{array}{l}\mathrm{E} \\
\mathrm{X} \\
\mathrm{P} \\
/ \\
\mathrm{F} \\
\mathrm{E} \\
\mathrm{M}\end{array}$ \\
\hline AHO & $\begin{array}{c}63.9 \\
3\end{array}$ & 69.2 & 0.92 & 21 & 13.5 & 1.56 \\
\hline AH1 & 69.5 & 72.6 & 0.96 & 13 & 12.8 & 1.02 \\
\hline $\mathrm{AH} 4$ & 64.7 & 75.7 & 0.85 & 9.83 & 12.1 & 0.81 \\
\hline BH0 & $\begin{array}{c}122 . \\
2\end{array}$ & 129.9 & 0.94 & 13.32 & 10.8 & 1.23 \\
\hline BH1 & 130 & 134.8 & 0.96 & 14.11 & 10.2 & 1.38 \\
\hline BH4 & 118 & 139.2 & 0.85 & 12.86 & 9.8 & 1.31 \\
\hline & Average & & 0.91 & --- & --- & 1.22 \\
\hline
\end{tabular}

The average yield load and deflection results based on experimental data are $9 \%$ and $22 \%$ lower and higher than the finite element analysis results respectively.

It can be seen that for strengthened reinforced HSC tested beams, the finite element model predicts the load and deflection with reasonably good accuracy. However, the main difference between experimental data and results gained from finite element analysis could be due to the:

- Limited number of elements in FEM. The larger number of elements, the more accurate the analysis results. Since non-linear analysis was run, increasing the number of elements could increase the analysis time dramatically.

- By using idealized stress-strain relationship of concrete, steel and FRP, the possibility of having errors will be increased.

\section{CRACK PATTERN AT SERVICEABILITY LOAD CONDITION}

The cracks distributions correspond to yield stress of tensile bars for series B test beams are shown in Fig. 7. As seen in Fig. 7, load step number for each load increment written at right side of crack and for yield load, it is 11,10 and 10 for $\mathrm{BH} 0, \mathrm{BH} 1$ and $\mathrm{BH} 4$ respectively. For the same stress level of the tensile 
bars, the flexural crack spacing in constant moment zone is $112 \mathrm{~mm}$ in $\mathrm{BH} 0$ and about $75 \mathrm{~mm}$ in BH1 and BH4 beam. These types of cracks were predominantly vertical and perpendicular to the direction of the maximum principal stress induced by pure moment. Flexural-shear crack accrued outside the constant moment zone as the load was increased and shear stress became more important. The tensile reinforcement ratio shows an important influence on the crack width: A smaller crack width is obtained for strengthened beams with a higher reinforcement ratio. In fact, a higher reinforcement ratio can accept bigger stress at cracking, tempering the crack initiation.
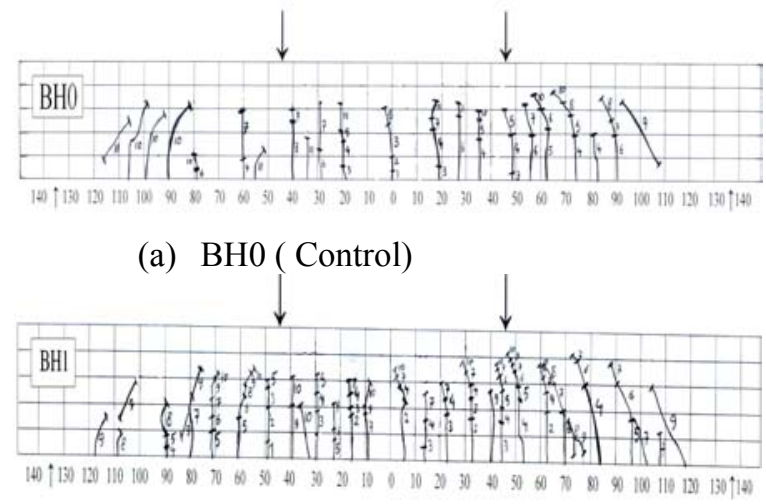

(b) $\mathrm{BH} 1$

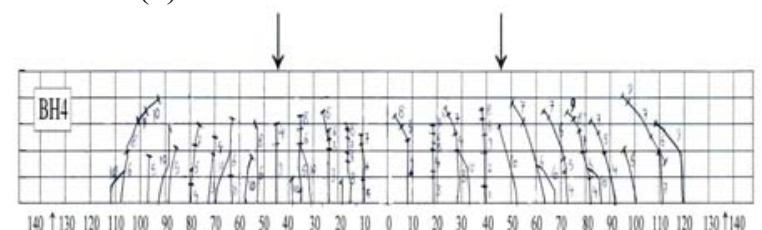

(c) $\mathrm{BH} 4$

Fig. 7: Crack Patterns of Control and CFRP Strengthened Beams at Yield State

The concrete was not initially pre-cracked and the development of the cracks during the reinforcement test is highly influenced by the number of CFRP layer. The occurrence of first crack was delayed and more diffuse. The tension steel in control beams $\mathrm{AHO}$ and $\mathrm{BH} 0$ reached its yield strength before the compressive strain in concrete reached 0.003 . For control beams after the first visible cracks observed, the cracking became extensive and crack widths increased steadily. The shape of the load deflection curves indicates a loss of stiffness at a load of approximately $64 \mathrm{kN}$ for $\mathrm{AH} 0$ and $122 \mathrm{KN}$ for BH0. This was due to yielding of the tensile reinforcement and occurred at a mid-span deflection of $21 \mathrm{~mm}$ for AH0 and $13.3 \mathrm{~mm}$ for BH0.
From the experimental observation, it can be seen that the bond between FRP and concrete is strong enough to ensure the rupture of the composites, thus when four or less than four layers of carbon fiber are applied, the bond problem is not the controlling factor for failure, thus the force in FRP will reach its ultimate tensile capacity when the beam fails and merge the concrete node with the FRP node in finite element model is a true assumption.

\section{MOMENT-STRAIN RESPONSE}

The experimental and analytical moment versus concrete compression strain at mid-span for both $\mathrm{A}$ and B series are plotted and shown in Figs. 8, 9. There is a similar increase in strain for all the beams at low moments. However, cracking of the concrete in the tension zone results in larger increments of strain in the control specimens. For these beams, concrete strain varies almost linearly with moment, after initial cracking, until yielding of the tension steel. On the other hand, the extreme compressive strain of concrete fiber in the strengthened beams with the increased number of layers of the CFRP sheet remains more or less linear up to yield and is not significantly affected by concrete cracking. These results demonstrate that the effect of the strengthening plate is to reduce strain in the compression fibers of the concrete. The presence of the plate draws the neutral axis lower in the section and, hence, places a greater volume of concrete in compression, resulting in lower strain (see Figs. 8, 9) and enabling a more efficient use of the existing material. Thus, externally bonded CFRP plates may also be beneficially used to reduce concrete compressive stresses, in addition to acting as additional tensile reinforcement.

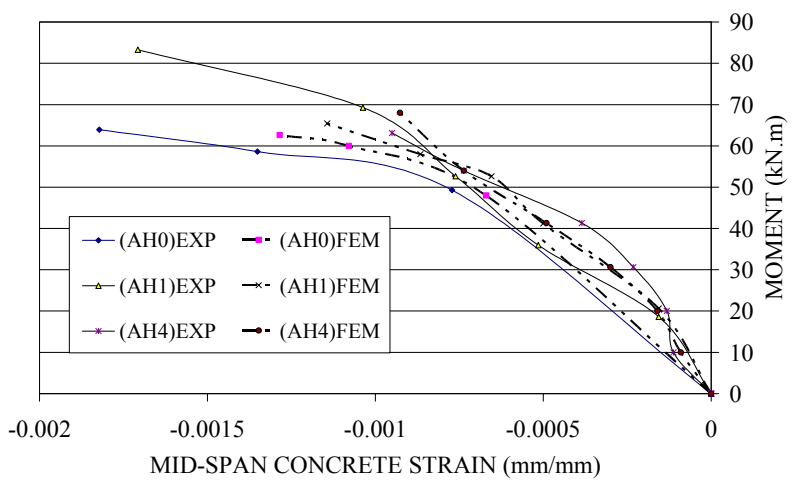

Fig. 8: Experimental and Analytical Load vs. Concrete Strain at Mid-Span for A Group 


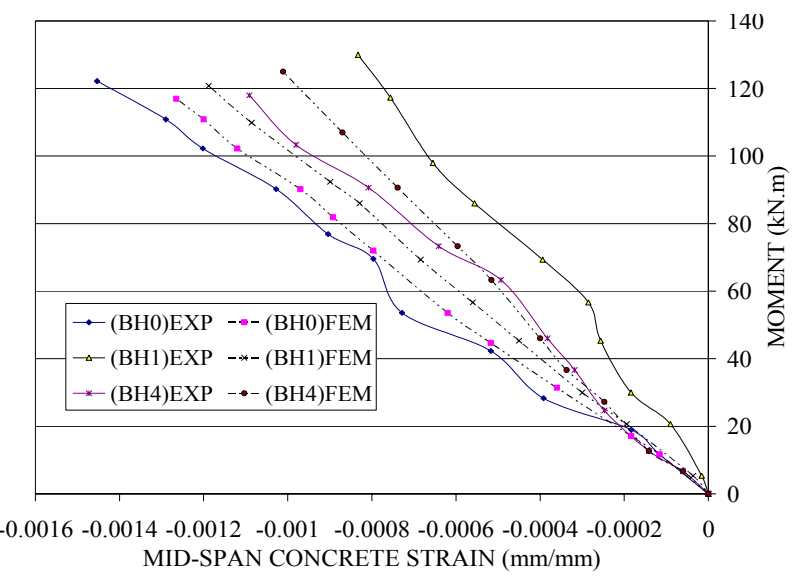

Fig. 9: Experimental and Analytical Load vs. Concrete Strain at Mid-Span for B Group

The relationship between concrete, CFRP and tensile bar steel strains (measured at mid-span and load point section) and applied yield moment for $\mathrm{AH} 4$ and BH4 beams measured from experimental study are plotted in Figs. 10, 11.

For beams $\mathrm{AH} 4$ and $\mathrm{BH} 4$, the tensile steel and CFRP strains are essentially the same at loads below cracking of the concrete. After cracking, the strains in steel exceeded those of the CFRP laminate. As the load approached the yielding load for the strengthened beam, the strains in steel increased more rapidly than those in the CFRP. This is because the CFRP had begun to debond from the concrete surface nearby cracks. It was noted that the tensile steels strains were always higher than the CFRP strains (see Figs. 10, 11).

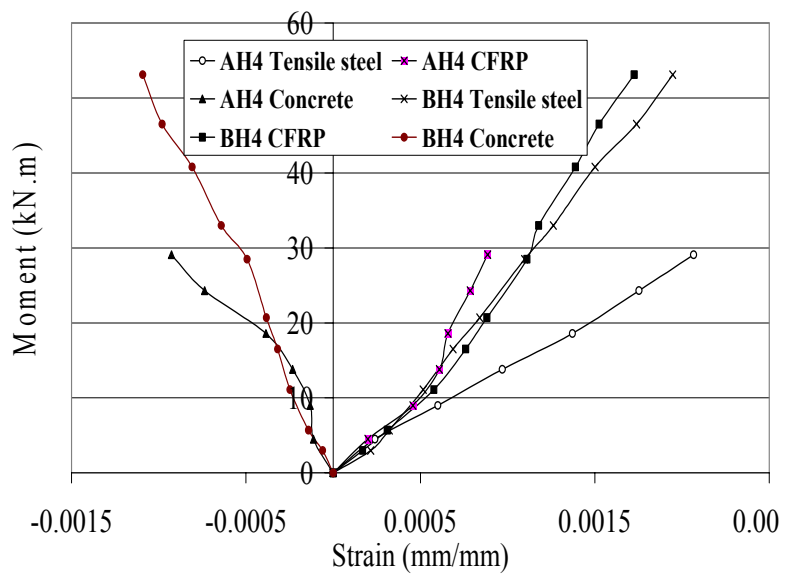

Fig. 10: Moment-Strain Curves of CFRP, Tensile Steel and Extreme Top Concrete Fiber for Beam AH4 and BH4 at Mid-Span Section

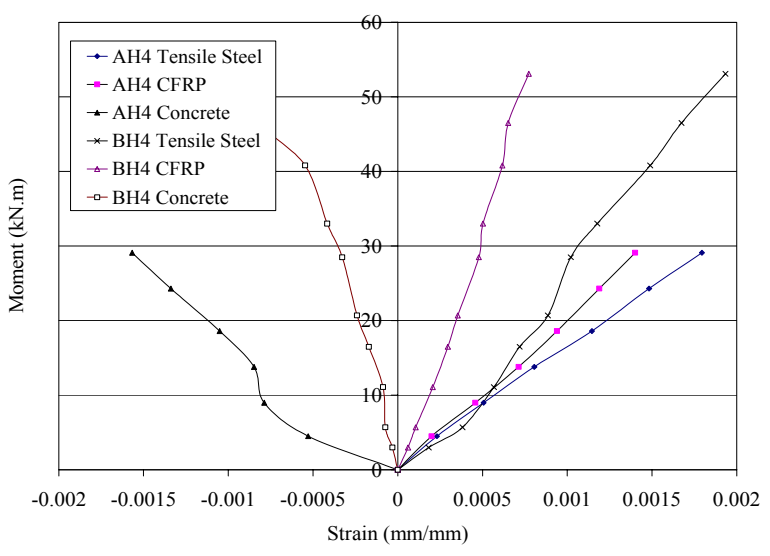

Fig. 11: Moment-Strain Curves of CFRP, Tensile Steel and Extreme Top Concrete Fiber for Beam AH4 and BH4 at Load Point Section

\section{SERVICEABILITY PERFORMANCE BASED ON EXPERIMENTAL RESULTS}

The widths of cracks in flexural members depend upon crack spacing, the quality of the bond between concrete, reinforcing bars and FRPs, and above all, strain in reinforcement. For steel-reinforced sections, ACI 318 [13], requires that the nominal moment strength, multiplied by the strength reduction factor $=0.9$, be equal to or greater than the moment $\mathrm{M}_{\mathrm{s}}$ at service multiplied by an appropriate load factor. The same code requires load factor of 1.4 and 1.7 for dead load and live loads, respectively. Considering an average load factor of 1.55 , the service stress in steel is $(0.9 / 1.55)$ times the specified yield stress. This is approximately equal to $60 \%$ of the specified yield stress.

For the steel used in this paper the specified yield stress is about $400 \mathrm{MPa}(60 \mathrm{ksi})$; the resulting maximum strain in the reinforcement at service is approximately $1200 \times 10^{-6}$. When the service strain in steel is permitted to reach $1200 \times 10^{-6}$, a width of cracks of $0.4 \mathrm{~mm}(0.016$ in.) is allowed in codes and standards.

Fig. 12 present the maximum observed crack width versus the maximum applied yield loads for tested beams.

For serviceability limit state during the beams test, the experimental values of steel tensile strain $\left(\varepsilon_{S}\right)$, the extreme layer of concrete compressive strain $\left(\varepsilon_{c}\right)$, strain of FRP, crack width and deflection are measured and given in Table 3.

Table 4 shows the normalized experimental values of steel tensile strain $\left(\varepsilon_{S}\right)$, the extreme layer of concrete compressive strain $\left(\varepsilon_{c}\right)$, strain of FRP, crack width and deflection for serviceability limit state. 
Am. J. Applied Sci., 4 (9): 725-735, 2007

Table 3: Experimental Values at Serviceability Limit State for Mid-Span (Sec. 1) and Load Point (Sec. 2) Section

\begin{tabular}{|c|c|c|c|c|c|c|c|c|c|c|}
\hline \multirow{3}{*}{$\underbrace{\exists}_{\exists} \underset{\Omega}{\Xi}$} & \multirow{3}{*}{ 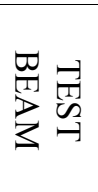 } & \multirow{3}{*}{$\begin{array}{l}\text { LOAD } \\
(\mathrm{KN})\end{array}$} & \multicolumn{6}{|c|}{ STRAIN $\times 10^{-6}(\mathrm{~mm} / \mathrm{mm})$} & \multirow{2}{*}{\multicolumn{2}{|c|}{$\begin{array}{c}\text { DEFLECTION } \\
(\mathrm{mm})\end{array}$}} \\
\hline & & & \multicolumn{2}{|c|}{ TENSILE BAR } & \multicolumn{2}{|c|}{ CONCRETE } & \multicolumn{2}{|c|}{ FRP } & & \\
\hline & & & Sec. 1 & Sec. 2 & Sec. 1 & Sec. 2 & Sec. 1 & Sec. 2 & Sec. 1 & Sec. 2 \\
\hline \multirow{3}{*}{0.1} & AH0 & 2.83 & 83 & 30 & 55 & 57 & - & - & 0.52 & 0.4 \\
\hline & AH1 & 14.15 & 218 & 378 & 186 & 209 & 176 & 863 & 2.03 & 1.62 \\
\hline & AH4 & 30.66 & 969 & 806 & 232 & 848 & 609 & 714 & 4.34 & 3.74 \\
\hline \multirow{3}{*}{0.2} & AH0 & 5.67 & 167 & 65 & 110 & 115 & - & - & 1.1 & 0.85 \\
\hline & AH1 & 28.3 & 436 & 815 & 371 & 467 & 354 & 1840 & 4.1 & 3.6 \\
\hline & AH4 & 72.7 & 2306 & 2049 & 935 & 1655 & 910 & 1499 & 10.98 & 9.27 \\
\hline \multirow{4}{*}{0.3} & AH0 & 8.5 & 250 & 100 & 165 & 179 & - & - & 1.61 & 1.31 \\
\hline & $\mathrm{AH} 1$ & 42.45 & 654 & 1389 & 557 & 719 & 530 & 2998 & 6.11 & 6.34 \\
\hline & AH4 & 82.67 & 3322 & 6600 & 1155 & 1758 & 1504 & 2141 & 14.19 & 11.95 \\
\hline & AH0 & 11.5 & 340 & 132 & 220 & 230 & - & - & 2.2 & 1.72 \\
\hline \multirow[t]{3}{*}{0.4} & AH1 & 52.64 & 617 & 1631 & 761 & 772 & 778 & 3426 & 8.33 & 7.5 \\
\hline & AH4 & 92.66 & 4338 & 11152 & 1374 & 1861 & 2098 & 2784 & 17.39 & 14.63 \\
\hline & BH0 & 7.66 & 101 & 119 & 75 & 1098 & - & - & 0.55 & 0.48 \\
\hline \multirow[t]{3}{*}{0.1} & BH1 & 30 & 520 & 535 & 184 & 701 & 207 & 105 & 2.43 & 2.62 \\
\hline & $\mathrm{BH} 4$ & 36.7 & 687 & 720 & 318 & 170 & 760 & 296 & 4.04 & 3.56 \\
\hline & BH0 & 15.3 & 202 & 238 & 149 & 2202 & - & - & 1.09 & 1.08 \\
\hline \multirow[t]{3}{*}{0.2} & BH1 & 56.7 & 912 & 914 & 285 & 801 & 317 & 172 & 5.19 & 5.11 \\
\hline & $\mathrm{BH} 4$ & 63.33 & 1097 & 1022 & 493 & 327 & 1111 & 479 & 6.95 & 6.18 \\
\hline & BH0 & 28.3 & 481 & 480 & 392 & 2405 & - & - & 2.32 & 2.13 \\
\hline \multirow[t]{3}{*}{0.3} & BH1 & 86 & 1331 & 1314 & 556 & 981 & 439 & 244 & 8.2 & 7.8 \\
\hline & BH4 & 90.7 & 1502 & 1490 & 808 & 546 & 1389 & 618 & 9.89 & 8.86 \\
\hline & BH0 & 42.29 & 728 & 721 & 517 & 2576 & - & - & 3.91 & 3.59 \\
\hline \multirow[t]{2}{*}{0.4} & BH1 & 98 & 1500 & 1472 & 655 & 1129 & 452 & 232 & 9.5 & 8.89 \\
\hline & BH4 & 126 & 2347 & 2527 & 1500 & 962 & 1886 & 771 & 14.34 & 12.81 \\
\hline
\end{tabular}

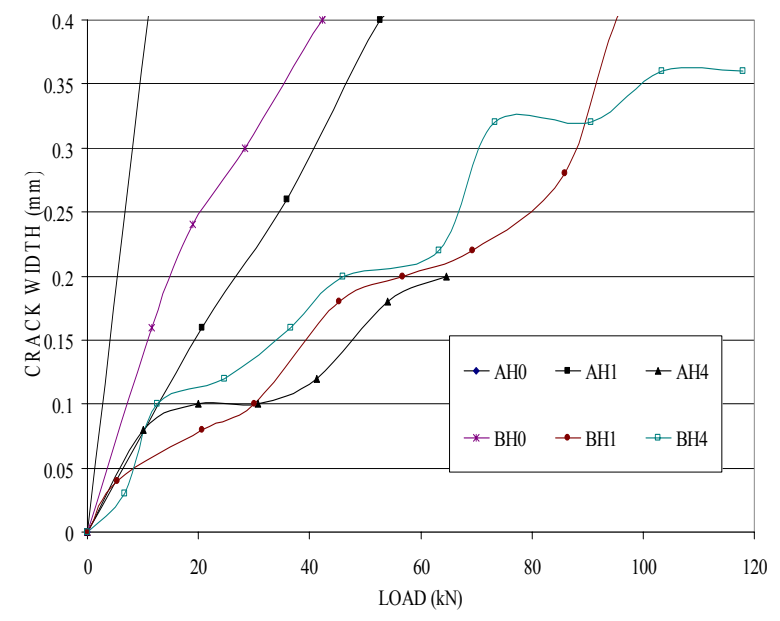

Fig. 12: Experimental Crack Width versus Applied Load for Tested Beams

The tensile bar and concrete extreme compressive strain values are converted in terms of stress for different environmental flexural crack widths (i.e., $0.1,0.2,0.3$ and $0.4 \mathrm{~mm}$ ) permitted in the current codes [13] and the obtained values are shown in Table 5 for mid-span (Sec. 1) and load point (Sec. 2) section. Also for more convenient, the ratios of $f_{s} / f_{y}$ and $f_{c} / f^{\prime \prime}$ are presented in Table 5

As general for normal strength concrete (NSC), the analysis of section may be considered as linear, when coefficient of $f_{c} / f^{\prime}{ }_{c}$ and $f_{s} / f_{y}$ are not exceed the values of 0.5 and 0.62 respectively. Although in literature, no suggestion was founded for HSC [17] flexural beams however, here the same coefficients are assumed for concrete and steel in HSC beams. Based on this assumption, it is obvious that, irrespective of the amount of $\rho, \rho_{.}^{\prime} f_{y}, f_{c}^{\prime}$, for all tested beams at mid-span section, the coefficient $f_{c} / f_{c}^{\prime}$ is equal to or less than 0.5 for permissible crack widths of 0.1 to $0.3 \mathrm{~mm}$. 
Am. J. Applied Sci., 4 (9): 725-735, 2007

Table 4: Normalized Test Results Serviceability Limit State for Mid-Span and Load Point Section

\begin{tabular}{|c|c|c|c|c|c|c|c|c|}
\hline \multirow{3}{*}{ CRACK WIDTH (mm) } & \multirow{3}{*}{$\begin{array}{l}\text { TEST } \\
\text { BEAM }\end{array}$} & \multirow{3}{*}{$\begin{array}{l}\text { LOAD } \\
(\mathrm{KN})\end{array}$} & \multicolumn{4}{|c|}{ STRAIN $\times 10^{-6}(\mathrm{~mm} / \mathrm{mm})$} & \multirow{2}{*}{\multicolumn{2}{|c|}{$\begin{array}{l}\text { DEFLECTION } \\
(\mathrm{mm})\end{array}$}} \\
\hline & & & \multicolumn{2}{|c|}{ TENSILE BAR } & \multicolumn{2}{|c|}{ CONCRETE } & & \\
\hline & & & Sec. 1 & Sec. 2 & Sec. 1 & Sec. 2 & Sec. 1 & Sec. 2 \\
\hline \multirow{3}{*}{0.1} & AH0 & 1 & 1 & 1 & 1 & 1 & 1 & 1 \\
\hline & AH1 & 5 & 2.63 & 12.60 & 3.38 & 3.67 & 3.9 & 4.05 \\
\hline & AH4 & 10.83 & 11.67 & 26.87 & 4.22 & 14.88 & 8.35 & 9.35 \\
\hline \multirow{3}{*}{0.2} & AHO & 1 & 1 & 1 & 1 & 1 & 1 & 1 \\
\hline & AH1 & 4.91 & 2.61 & 12.54 & 3.37 & 4.06 & 3.73 & 4.24 \\
\hline & AH4 & 12.82 & 13.81 & 31.52 & 8.5 & 14.39 & 9.98 & 10.91 \\
\hline \multirow{3}{*}{0.3} & AHO & 1 & 1 & 1 & 1 & 1 & 1 & 1 \\
\hline & AH1 & 4.94 & 2.61 & 13.89 & 3.37 & 4.02 & 3.79 & 4.84 \\
\hline & AH4 & 9.72 & 13.29 & 66.00 & 7 & 9.82 & 8.81 & 9.12 \\
\hline \multirow{3}{*}{0.4} & AH0 & 1 & 1 & 1 & 1 & 1 & 1 & 1 \\
\hline & AH1 & 4.58 & 1.81 & 12.36 & 3.46 & 3.36 & 3.79 & 4.36 \\
\hline & AH4 & 8.06 & 12.76 & 84.48 & 6.24 & 8.09 & 7.9 & 8.51 \\
\hline \multirow{3}{*}{0.1} & BH0 & 1 & 1 & 1 & 1 & 1 & 1 & 1 \\
\hline & BH1 & 3.92 & 5.15 & 4.50 & 2.45 & 0.64 & 4.42 & 5.46 \\
\hline & BH4 & 4.79 & 6.80 & 6.05 & 4.24 & 0.15 & 7.35 & 7.42 \\
\hline \multirow{3}{*}{0.2} & BH0 & 1 & 1 & 1 & 1 & 1 & 1 & 1 \\
\hline & BH1 & 3.71 & 4.51 & 3.84 & 1.91 & 0.36 & 4.76 & 4.73 \\
\hline & BH4 & 4.14 & 5.43 & 4.29 & 3.31 & 0.15 & 6.38 & 5.72 \\
\hline \multirow{3}{*}{0.3} & BH0 & 1 & 1 & 1 & 1 & 1 & 1 & 1 \\
\hline & BH1 & 3.04 & 2.77 & 2.74 & 1.42 & 0.41 & 3.53 & 3.66 \\
\hline & BH4 & 3.20 & 3.12 & 3.10 & 2.06 & 0.23 & 4.26 & 4.16 \\
\hline \multirow{3}{*}{0.4} & BH0 & 1 & 1 & 1 & 1 & 1 & 1 & 1 \\
\hline & BH1 & 2.32 & 2.06 & 2.04 & 1.27 & 0.44 & 2.43 & 2.48 \\
\hline & BH4 & 2.98 & 3.22 & 3.50 & 2.90 & 0.37 & 3.67 & 3.57 \\
\hline
\end{tabular}

Table 5: Experimental Values of Concrete and Steel Strain and Stress for Different Permissible Flexural Crack Widths of the Control and FRP Strengthened Beams

\begin{tabular}{|c|c|c|c|c|c|c|c|c|c|}
\hline \multirow[t]{2}{*}{$\begin{array}{l}\text { CRACK WIDTH } \\
(\mathrm{mm})\end{array}$} & \multirow[t]{2}{*}{$\begin{array}{l}\text { TEST } \\
\text { BEAM }\end{array}$} & \multicolumn{2}{|c|}{$\begin{array}{c}\text { TENSILE BAR } \\
\text { STRESS } \\
f_{s}(\mathrm{Mpa})\end{array}$} & \multicolumn{2}{|c|}{$f_{s} / f_{y}$} & \multicolumn{2}{|c|}{$\begin{array}{c}\text { CONCRETE } \\
\text { STRESS } \\
f_{c}(\mathrm{Mpa})\end{array}$} & \multicolumn{2}{|c|}{$f_{c} / f^{\prime}{ }_{c}$} \\
\hline & & Sec. 1 & Sec. 2 & Sec. 1 & Sec. 2 & Sec. 1 & Sec. 2 & Sec. 1 & Sec. 2 \\
\hline \multirow{3}{*}{0.1} & AH0 & 16.6 & 6 & 0.04 & 0.01 & 2.06 & 2.14 & 0.03 & 0.03 \\
\hline & AH1 & 43.6 & 75.6 & 0.11 & 0.18 & 6.88 & 7.71 & 0.09 & 0.10 \\
\hline & AH4 & 193.8 & 161.2 & 0.47 & 0.39 & 8.54 & 29.10 & 0.11 & 0.38 \\
\hline \multirow{4}{*}{0.2} & AH0 & 33.4 & 13 & 0.08 & 0.03 & 4.10 & 4.29 & 0.05 & 0.06 \\
\hline & AH1 & 87.2 & 163 & 0.21 & 0.40 & 13.44 & 16.74 & 0.17 & 0.22 \\
\hline & AH4 & 410 & 409.8 & 1 & 1 & 31.76 & 51.43 & 0.41 & 0.67 \\
\hline & AH0 & 50 & 20 & 0.12 & 0.05 & 6.12 & 6.62 & 0.08 & 0.09 \\
\hline \multirow[t]{2}{*}{0.3} & AH1 & 130.8 & 277.8 & 0.32 & 0.68 & 19.77 & 25.05 & 0.26 & 0.33 \\
\hline & AH4 & 410 & 410 & 1 & 1 & 38.21 & 53.90 & 0.50 & 0.70 \\
\hline \multirow[t]{2}{*}{0.4} & $\mathrm{AH} 0$ & 68 & 26.4 & 0.17 & 0.06 & 8.11 & 8.47 & 0.11 & 0.11 \\
\hline & \multicolumn{8}{|c|}{733} & 0.35 \\
\hline
\end{tabular}


Am. J. Applied Sci., 4 (9): 725-735, 2007

\begin{tabular}{cccccccccc} 
& AH4 & 410 & 410 & 1 & 1 & 44.25 & 56.29 & 0.57 & 0.73 \\
0.1 & BH0 & 20.2 & 23.8 & 0.05 & 0.06 & 2.81 & 36.58 & 0.04 & 0.48 \\
& BH1 & 104 & 107 & 0.25 & 0.26 & 6.81 & 24.47 & 0.09 & 0.32 \\
& BH4 & 137.4 & 144 & 0.34 & 0.35 & 11.59 & 6.30 & 0.15 & 0.08 \\
0.2 & BH0 & 40.4 & 47.6 & 0.10 & 0.12 & 5.53 & 63.58 & 0.07 & 0.83 \\
& BH1 & 182.4 & 182.8 & 0.44 & 0.45 & 10.43 & 27.64 & 0.14 & 0.36 \\
& BH4 & 219.4 & 204.4 & 0.54 & 0.50 & 17.62 & 11.91 & 0.23 & 0.15 \\
0.3 & BH0 & 96.2 & 96 & 0.23 & 0.23 & 14.17 & 67.48 & 0.18 & 0.88 \\
& BH1 & 266.2 & 262.8 & 0.65 & 0.64 & 19.73 & 33.14 & 0.26 & 0.43 \\
& BH4 & 300.4 & 298 & 0.73 & 0.73 & 27.86 & 19.40 & 0.36 & 0.25 \\
& BH0 & 145.6 & 144.2 & 0.36 & 0.35 & 18.43 & 70.51 & 0.24 & 0.92 \\
& BH1 & 300 & 294.4 & 0.73 & 0.72 & 22.99 & 37.47 & 0.30 & 0.49 \\
& BH4 & 410 & 410 & 1 & 1 & 47.55 & 32.57 & 0.62 & 0.42 \\
\hline
\end{tabular}

\section{CONCLUSIONS}

The major conclusions derived from this experimental study are given as follows:

1. The finite element model results show good agreement with observations and data from the experimental full-scale beam tests. This numerical study can be used to predict the serviceability condition of reinforced HSC beam strengthened with FRP

2. The results of tests performed in this study indicate that, strengthening reduced crack width in the high strength reinforced concrete beams at all load levels.

3. The extreme compressive strain of concrete fiber in the strengthened beams with the increased number of CFRP layers remains more or less linear at serviceability limit state conditions of the beam and is not significantly affected by concrete cracking

4. The results obtained demonstrate that the effect of the strengthening plate is to reduce strain in the compression fibers of the HSC beams.

5. By Comparing deformations in control beams (reinforced with steel only), beams reinforced with steel and strengthened by CFRP, have shown less deformation capacity

6. As the amount of steel reinforcement increases, the decrease of deflection that provided by the carbon FRP external reinforcement decreases. The same amount of CFRP reinforcement more than 53\% the yield deflection of a lightly reinforced beam $(\rho=1.2 \%)$, but only decreased by $3.6 \%$ the yield deflection of a moderately reinforced beam $(\rho=2.4 \%)$.

7. It is seen that average yield load results based on experimental data are $9 \%$ lower than the results gotten from finite element analysis but the average yield deflection results based on experimental tests are $22 \%$ higher than the FEM results

8. For the same stress level of the tensile bars, the flexural crack spacing in constant moment zone is $112 \mathrm{~mm}$ in control beam and about $75 \mathrm{~mm}$ in strengthened beams, in other words at same serviceability load, the crack spacing is not depended on the area of the FRP sheet.

\section{REFERENCES}

1. Toutanji, H., L. Zhao and E. Anselm, 2006. Verifications of design equations of beams externally strengthened with FRP composites, Journal of Composites for Construction 10(3): 254264

2. Xiong, G.J., X. Jiang, J.W. Liu and L. Chen, 2007. A way for preventing tension delamination of concrete cover in midspan of FRP strengthened beams, Journal of Construction and Building Materials 21:402-408

3. Oh, B.H., J.Y. Cho and D.G. Park, 2003. Static and fatigue behavior of reinforced concrete beams strengthened with steel plates for flexure, Journal of Structural Engineering 129(4): 527-535.

4. Chahrour, A. and K. Soudki, 2005. Flexural response of reinforced concrete beams strengthened with end-anchored partially bonded carbon fiber-reinforced polymer strips, Journal of Composites for Construction 9(2): 170-177

5. Lee, T.K., D.E. Austin, and J.L. Ma, 2004. Ductile design of reinforced concrete beams retrofitted with fiber reinforced polymer plates, Journal of Composites for Construction 8(6): 489-500

6. Pilakoutas, K., K. Neocleous, and M. Guadagnini, 2002. Design philosophy issues of fiber reinforced polymer reinforced concrete structures, Journal of Composites for Construction 6(3): 154-161 
7. Alagusundaramoorthy, P., I.E. Harik, and C.C. Choo, 2003. Flexural behavior of $\mathrm{R} / \mathrm{C}$ beams strengthened with carbon fiber reinforced polymer sheets or fabric, Journal of Composites for Construction 7(4): 292-301

8. Saadatmanesh, H. and M.R. Ehsani, 1991. RC beams strengthened with GFRP plates, I: experimental study, Journal of Structural Engineering, 117(11): 3417-3433

9. Malek, A.M., H. Saadatmanesh and M.R. Ehsani, 1998. Prediction of failure load of $\mathrm{R} / \mathrm{C}$ beams strengthened with FRP plate due to stress concentration at the plate end, ACI Structural Journal 95(2): 142-152

10. Kachlakev, D., Miller, T., Chansawat, K., and Potisuk, T., 2001. Finite element modeling of reinforced concrete structures strengthened with FRP laminates, SPR 316, Oregon Department of Transportation Research Group 200 Hawthorne SE, Suite B-240 Salem, and Federal Highway Administration 400 Seventh Street SW Washington, DC 20590

11. Fanning, P.J. and O. Kelly, 2001. Ultimate response of RC beams strengthened with CFRP plates, Journal of Composites for Construction 5(2): 122-127.
12. Gao, B., C.K.Y. Leung and J.K. Kim, 2007. Failure diagrams of FRP strengthened RC beams, Journal of Composite Structures 77: 493-508

13. American Concrete Institute (ACI), 2005, Building Code Requirements for Structural Concrete (ACI 318-05). ACI Committee 318 Report, Farmington Hills, Michigan

14. ANSYS, I. (2003). ANSYS Manual Set. ANSYS, Inc., Canonsburg, PA 15317, USA

15. Uy, B., 1998. Local and post-local buckling of concrete filled steel welded box columns, Journal of Constructional Steel Research 47:47-72.

16. Chansawat, K., S. Yim, and T. Miller, 2006. Nonlinear finite element analysis of a FRPstrengthened reinforced concrete bridge, Journal of Bridge Engineering 11(1): 21-32

17. American Concrete Institute (ACI), 1992. State-ofthe-art report on high-strength concrete, ACI Committee 363 Report, Detroit. 